\section{A utilização da técnica de grupo focal: um estudo com mulheres quilombolas}

\author{
Focus groups with women from quilombo \\ communities in Brazil
}

\section{El uso de la técnica de grupo focal: un estudio con mujeres quilombolas}

\author{
Lisie Alende Prates 1 \\ Fernando Gomes Ceccon 2 \\ Camila Neumaier Alves 3 \\ Laís Antunes Wilhelm 1 \\ Carolina Carbonell Demori 3 \\ Silvana Cruz da Silva 4 \\ Lúcia Beatriz Ressel 1
}

\author{
1 Programa de Pós-graduação \\ em Enfermagem, \\ Universidade Federal de \\ Santa Maria, Santa Maria, \\ Brasil. \\ 2 Programa de Pós-graduação \\ em Educação Física, \\ Universidade Federal de \\ Santa Maria, Santa Maria, \\ Brasil. \\ 3 Programa de Pós-graduação \\ em Enfermagem, \\ Universidade Federal de \\ Pelotas, Pelotas, Brasil. \\ 4 Universidade Federal do Rio \\ Grande do Sul, Porto Alegre, \\ Brasil. \\ Correspondência \\ L. A. Prates \\ Rua Manoel Gomes Carneiro \\ 117, apto. 204, Santa Maria, \\ RS 97050-470, Brasil. \\ lisiealende@hotmail.com
}

\begin{abstract}
This article discusses an experience using the focus group technique with women from a quilombo, or community of descendants of African slaves in Brazil. This is a descriptive qualitative anthropological study of 13 women from a quilombo in rural Rio Grande do Sul State, Brazil. The focus group technique allowed an approach, interaction, and exchange of knowledge, experiences, perceptions, and feelings, in addition to problematization and in-depth discussion concerning the meaning of women's health care in the quilombo. The focus group was a prime space for learning and understanding the life experiences of quilombola women and the meanings they assigned to the experiences. In order to use the focus group technique, researchers must display creativity, sensitivity, attention, respect, nonjudgmental attitudes, flexibility, prior preparation, and knowledge of the technique and specific study topic.
\end{abstract}

African Continental Ancestry Group; Focus Groups; Women's Health

\section{Resumo}

Este estudo tem como objetivo discutir acerca da experiência de utilização da técnica de grupo focal em um estudo com mulheres quilombolas. Pesquisa qualitativa descritiva, com vertente antropológica, realizada com 13 mulheres de uma comunidade quilombola, localizada no interior do Estado do Rio Grande do Sul, Brasil. A utilização da técnica de grupo focal permitiu aproximação, interação, troca de saberes, experiências, percepções e sentimentos, além da problematização e aprofundamento acerca do significado de cuidado à saúde da mulher quilombola. O grupo focal representou um espaço propício para o conhecimento e a compreensão das experiências de vida das mulheres quilombolas, bem como os significados atribuídos por elas às vivências. A técnica de grupo focal exige dos pesquisadores criatividade, sensibilidade, atenção, respeito, ausência de julgamentos, flexibilidade, preparação prévia e conhecimento da técnica e da temática de estudo.

Grupo com Ancestrais do Continente Africano; Grupos Focais; Saúde da Mulher 


\section{Introdução}

Este artigo resultou da dissertação de mestrado intitulada O Olhar Feminino sobre o Cuidado à Saúde da Mulher Quilombola, realizada com mulheres quilombolas 1 . A pesquisa de abordagem qualitativa teve como objetivo conhecer o significado do cuidado à saúde entre mulheres de uma comunidade quilombola e como questão norteadora "como é compreendido o significado de cuidado à saúde de mulheres quilombolas, de um município do interior do Rio Grande do Sul/ Brasil?".

Como a pesquisa envolvia uma temática imbuída de significações, valores e crenças, elaborados e construídos dentro de um grupo inserido em um contexto social, histórico e cultural, que possui suas particularidades, percepções e tradições, compreendeu-se a necessidade de utilizar um método de produção de dados que permitisse a manifestação de diferentes percepções e o aprofundamento coletivo acerca da temática proposta 2 . Nessa perspectiva, elencou-se o grupo focal.

O grupo focal consiste em uma técnica de produção dos dados que envolve a formação de um grupo com características comuns, dirigido por um moderador, que mantém os participantes centrados em uma discussão sobre determinado tema 3,4 . Com base nessa técnica, é possível a troca de ideias, experiências, sentimentos, crenças, comportamentos e pontos de vista, proporcionando a reflexão e, até mesmo, a mudança de opinião ou de fundamentação da posição inicial 2,5,6,7.

Nessa técnica, por meio da integração grupal, é possível compreender como são construídas as percepções, práticas cotidianas, representações e simbologias de um determinado grupo 2,8 . Pela técnica, produzem-se discussões grupais que permitem compreender a forma como os indivíduos veem o mundo e suas diferentes experiências de vida 2 .

Fundamentado nessas considerações, este artigo tem como objetivo apresentar a experiência de utilização da técnica de grupo focal com um grupo de mulheres de uma comunidade quilombola, no interior do Rio Grande do Sul, Brasil.

\section{Método}

Trata-se de um estudo de campo, do tipo descritivo, com abordagem qualitativa e vertente antropológica. Teve como cenário uma comunidade quilombola, localizada em um município no interior do Rio Grande do Sul.
O estudo foi desenvolvido com 13 mulheres, selecionadas de forma intencional, que vivenciavam períodos de vida entre a adolescência e a velhice. Os critérios de inclusão compreenderam mulheres quilombolas, residentes na comunidade cenário do estudo, com idade mínima de 12 anos (considerada como idade de início da adolescência, conforme o Estatuto da Criança e do Adolescente) e sem limitação máxima de idade. Os critérios de exclusão englobaram mulheres com limitações psicocognitivas que prejudicassem a compreensão e participação no estudo.

Para captação das participantes, inicialmente, foi realizada uma visita à comunidade quilombola, com vistas a explicar o projeto de pesquisa e convidar as mulheres que residiam no local, e que atendiam aos critérios de inclusão para participar do estudo. Nesse dia, foi também combinada a data do primeiro encontro.

A pesquisa foi realizada no mês de fevereiro do ano de 2014 e teve como técnica principal para a produção dos dados o grupo focal, do tipo estruturado, com moderação não diretiva, desenvolvido em três encontros. O grupo focal consiste em uma técnica de pesquisa que utiliza materiais de estímulo, comumente dinâmicas, para fomentar e sustentar discussões em grupo, que permitam o intercâmbio de saberes e experiências entre os participantes $3,9,10$. Nesse sentido, valendo-se daqueles materiais, são realizadas, inicialmente, perguntas genéricas e, a seguir, elas são aprofundadas, direcionando para o foco do estudo 11.

Além do grupo focal, foi realizada uma entrevista semiestruturada, para caracterizar as participantes, e foram feitas anotações em diários de campo, os quais consistiram em instrumentos pessoais para anotações da moderadora e do observador sobre dados subjetivos, percepções, sentimentos e impressões pessoais antes, durante e após as sessões do grupo focal.

Foi apreciado e autorizado o Termo de Consentimento Livre e Esclarecido (TCLE) às participantes maiores de 18 anos e para os responsáveis pelas menores de 18 anos, que também assinaram o Termo de Assentimento. Este estudo foi aprovado em Comitê de Ética em Pesquisa, sob o número do processo 25345113.7.0000.5346, em 13 de dezembro de 2013.

Com a finalidade de preservar a identidade das participantes da pesquisa, elas foram identificadas conforme sistema alfanumérico, utilizando a letra "M". As falas das participantes foram transcritas na íntegra e os dados produzidos foram analisados e interpretados por meio da análise de conteúdo temática da proposta operativa 12 . 


\section{Resultados e discussão}

A comunidade em que foi desenvolvida a pesquisa foi certificada como comunidade remanescente quilombola no ano de 2012, pela Fundação Palmares. Encontrava-se distante 65 quilômetros da sede de um município e podia ser acessada por estrada de chão batido. No local, conviviam 28 famílias que totalizavam 101 sujeitos. Desses, 52 eram homens e 49 mulheres, subdivididos em 14 crianças, 33 jovens, 38 adultos e 16 idosos.

Em relação à infraestrutura, a comunidade dispunha de água por meio de poço artesiano há aproximadamente 10 anos, e luz elétrica há quatro anos a partir do Programa Brasil Quilombola com o Programa Luz Para Todos, criado pelo Governo Federal em 2003. Possuíam uma padaria, mantida pelas mulheres da comunidade, em que eram produzidos pães para comercialização. Na comunidade, havia um armazém e uma escola, mas não pertenciam ao quilombo. No local, não existiam serviços de saúde e nem atividades de lazer.

Assistentes sociais da Coordenadoria de Saúde do município-sede se deslocavam até o local, quinzenalmente, para realização de atividades pontuais. A Empresa de Assistência Técnica e Extensão Rural (EMATER) também desenvolvia algumas ações no local. No que se refere aos meios de transporte, havia apenas um ônibus de linha, que fazia seu trajeto até a comunidade duas vezes durante a semana. Os quilombolas desenvolviam o cultivo de hortas para consumo próprio.

Essa comunidade quilombola foi escolhida como cenário da pesquisa pelo entendimento de que, no local, existiam costumes, tradições e crenças perpetuados de forma intergeracional que foram culturalmente produzidos e influenciavam diretamente no cuidado à saúde da mulher quilombola.

O grupo focal foi utilizado como técnica principal para produção dos dados por considerar que ele permitiria o aprofundamento sobre o cuidado à saúde de mulheres quilombolas $\mathrm{e}$ também possibilitaria a manifestação de uma multiplicidade de pontos de vista e processos emocionais, por meio da aproximação, integração e envolvimento com um grupo pequeno e homogêneo $2,5,7$.

Os encontros contaram com a participação de uma moderadora e um observador, ambos iniciantes na técnica de grupo focal. Durante os encontros, a moderadora orientou a operacionalização do encontro, as etapas a serem percorridas e os objetivos propostos. Ela também introduziu a temática e algumas questões para aprofundá-la, e permitiu que todas as mulheres elaborassem suas análises e expusessem su- as percepções. Em alguns momentos, precisou intervir para manter e/ou retomar o foco das discussões e promover as trocas de saberes no grupo, especialmente quando alguma participante tentava dominar a discussão 13,14. Ao final de cada encontro, a moderadora elaborou, em conjunto com o grupo, a síntese e validação das informações e confirmou os pontos de vista apresentados $3,15,16$.

O observador do estudo controlou o tempo de cada encontro, auxiliou na organização e na sua condução e monitorou os gravadores 7,16,17. Ao longo do encontro, além das manifestações não verbais, o observador também registrou no seu diário de campo algumas palavras-chave das falas das participantes, que pudessem auxiliar no momento da transcrição 9 .

Verificou-se que a presença do observador mostrou-se fundamental para a realização da técnica. Todavia, autores 18 consideram que a figura do observador nem sempre é obrigatória, sendo a técnica, nesses casos, conduzida integralmente pelo moderador. Entretanto, no presente estudo, a participação do observador foi imprescindível para a boa condução da técnica, da mesma forma que em outros estudos encontrados na literatura $3,8,16$.

Destaca-se, ainda, que para realização dos encontros, a moderadora e o observador realizaram inúmeras leituras acerca da técnica de grupo focal, por compreenderem que sua atuação no grupo necessitava de muito preparo e instrumentalização em relação à técnica, além de conhecimento sobre a temática de estudo. Para identificarem os assuntos que deveriam ser trabalhados previamente, foi elaborado, anteriormente ao recrutamento e convite das participantes, um roteiro com um guia de temas que nortearam e sistematizaram os questionamentos e os objetivos de cada sessão de grupo focal.

Nesse roteiro, foram dispostos os questionamentos previstos para cada um dos encontros. Desse modo, para o primeiro encontro, as questões que nortearam a sessão foram: "Para você, o que significa cuidar da saúde? Como a saúde é cuidada na comunidade? O que você faz para cuidar de sua saúde vivendo nessa comunidade?". Para o segundo encontro, elaborou-se a questão: "Como você se sente sendo mulher quilombola vivendo nessa comunidade?", e, no terceiro encontro, foi adotado o seguinte questionamento: "Para você, o que é importante cuidar na saúde da mulher?".

Tal roteiro foi utilizado com total flexibilidade de forma a garantir que ao longo dos encontros pudessem ser feitos ajustes, sem desconsiderar os objetivos da pesquisa. Essa flexibilização se fez necessária, pois conforme a literatura 2 já previa, 
durante os debates, surgiram tópicos relevantes para as participantes e para a questão de estudo que não constavam no roteiro elaborado, mas que foram incorporados no momento grupal.

Após a organização do roteiro, foram tomados alguns cuidados que permearam todos os encontros, como o planejamento dos materiais específicos para as dinâmicas incentivadoras de discussão, manutenção dos gravadores (recarga das pilhas) e preparação dos lanches. Com todo o material organizado, encaminhou-se para o cenário do estudo e deu-se início à operacionalização da técnica. Vale comentar que, na primeira visita à comunidade quilombola, as participantes foram informadas quanto à temática de maneira geral (cuidado à saúde da mulher), a justificativa pela escolha delas como participantes do estudo, a rotina e a duração dos encontros. Em relação aos esclarecimentos, a literatura 2 não recomenda o repasse de informações minuciosas sobre o objeto da pesquisa aos participantes, a fim de evitar a elaboração de ideias prévias que possam vir a interferir nas discussões.

Nessa ocasião, ainda foi agendada a data, o horário e o local do primeiro encontro, sendo acordado que seria realizado na semana seguinte. As participantes também solicitaram que o segundo e terceiro encontros já fossem agendados, os quais, por decisão delas, estavam previstos para serem realizados, respectivamente, um dia após o primeiro e dois dias após o segundo. Após esses acordos, foi entregue a cada uma das participantes um cartão com um lembrete, contendo as informações acerca da data, local e horário do primeiro encontro.

Depois do convite para participação da pesquisa, os condutores do grupo focal discutiram sobre suas impressões frente à proximidade de realização da técnica e registraram suas percepções e sentimentos nos diários de campo. Os autores 16 consideram que momentos de diálogo e reflexão dentro da equipe são fundamentais no processo de coordenação do grupo focal. Esses momentos são fundamentais, pois conforme indica autor 9 , pesquisadores que são iniciantes na utilização do grupo focal comumente sentem-se inseguros pela aparente brevidade do roteiro e precisam se convencer de que seus questionamentos e materiais de estímulo para o debate são suficientes para incitar e sustentar a discussão grupal.

Dessa forma, mediante a preparação para os encontros e aprofundamento acerca da técnica na literatura 19 , a moderadora e o observador que inicialmente mostravam-se inseguros, após se preparem, se tranquilizaram para realização da técnica. Logo, ressalta-se que a preparação técnica para realização do grupo focal e científica acerca do tema em foco é essencial para a qualidade do trabalho a ser desenvolvido 11 .

No primeiro encontro, ao chegar à comunidade, pôde-se identificar que as participantes encontravam-se dispostas em cadeiras, em um formato circular, ao ar livre. Nesse dia, a temperatura estava elevada e isso influenciou na escolha delas em relação a um espaço aberto, mas restrito de movimento, dentro da comunidade. Embora os pesquisadores temessem que o ambiente pudesse prejudicar a gravação das falas, foi respeitada a escolha das participantes, por compreender que esse era o local onde se sentiam confortáveis e seguras para expor suas percepções, e que também não haveria interferência de movimento de outras pessoas ou de ruídos e sons 11 .

Autores 2,3,11,20,21,22 que utilizam grupo focal indicam que o ambiente organizado para o uso de tal técnica deve ser amplo, silencioso, confortável, com boa iluminação e ventilação, que possa assegurar a privacidade e a interação entre as participantes. Também afirmam que o local deve apresentar um espaço adequado para a realização das técnicas de debate e a disposição de assentos deve ser de forma circular, garantindo, assim, uma boa interação visual entre todos os envolvidos e a sensação a todos de fazer parte do grupo.

Assim, conforme mencionado, a disposição dos assentos foi arranjada pelas próprias participantes e pôde-se constatar que essa conformação facilitou a interação e o debate. Quanto ao local, embora não atendesse exatamente o indicado por autores que já usaram a técnica 11, para as participantes mostrava-se como o ideal. Além disso, não houve perda dos depoimentos, pois todas se encontravam próximas, o que facilitou a gravação de suas falas. Destaca-se, também, que não foram discutidos temas que necessitassem de um ambiente privativo para a exposição das falas das participantes. Portanto, mesmo não sendo possível contemplar todos os aspectos definidos na literatura, optou-se por manter o local definido pelo grupo, reconhecendo-se, desse modo, a necessidade de flexibilidade em relação ao espaço ${ }^{9}$.

Destaca-se ainda que ao final de todos os encontros foi realizada a audição das gravações e verificou-se que o ambiente não prejudicou o funcionamento dos gravadores. Haja vista que, durante os encontros, foram utilizados dois gravadores, dispostos em pontos diferentes, com intuito de garantir o bom registro das falas de todas as participantes, da mesma forma como sugerem os estudos 11,22.

No primeiro dia, foi realizada a leitura e entrega do TCLE e do Termo de Assentimento ao 
início e, ao final, foi desenvolvida uma entrevista semiestruturada para coletar dados complementares relativos à caracterização socioeconômica e de saúde das participantes.

Ainda que alguns autores 2,6,20 recomendem a confecção de crachás para a moderadora e o observador a fim de facilitar o reconhecimento das participantes, entendeu-se tal aspecto como desnecessário, pois ocorreu uma boa interação e aproximação entre todos, o que facilitou a memorização dos nomes. Nessa perspectiva, também se verificou que o cuidado em chamá-las pelo nome, durante a sessão grupal, auxiliou na construção do vínculo e qualificou a relação em grupo 16 .

Todos os encontros foram divididos em cinco momentos, em consonância com as orientações de estudo sobre grupo focal 16, assim otimizados: (1) cumprimentos iniciais e retomadas as ideias dos encontros anteriores; (2) apresentação dos objetivos do encontro atual; (3) realização da dinâmica para estimular a discussão; (4) debate; (5) apresentação da síntese e validação coletiva do encontro.

No primeiro momento da primeira sessão grupal, a moderadora e o observador apresentaram-se para o grupo e, a seguir, solicitaram que as participantes também fizessem o mesmo. Em seguida, foi feito um "contrato grupal", sendo solicitada pontualidade, assiduidade, respeito à fala da outra e sigilo das informações produzidas no grupo, além da permissão para gravação das falas, destacando que elas seriam transcritas, respeitando-se o anonimato das participantes 2,7,13,23.

No segundo momento, foram apresentados os objetivos e a operacionalização do encontro. Para iniciar o terceiro momento, desenvolveramse algumas dinâmicas e técnicas, dentro do propósito da pesquisa que permitiram introduzir a temática e iniciar o debate. Além de estimular o diálogo, as dinâmicas e técnicas escolhidas tiveram como propósito criar um clima agradável dentro do grupo e possibilitar a expressão de diferenças e semelhanças entre as participantes 2 .

Destacam-se algumas dinâmicas deflagradoras de debate, como a brainstorming, na qual as participantes foram convidadas a expressar, com o menor número de palavras, a sua concepção sobre o termo "cuidado". No segundo encontro, utilizou-se a técnica de desenho, para que as participantes pudessem expressar como se sentiam sendo mulheres quilombolas vivendo naquela comunidade. No último encontro, a dinâmica estimuladora de debate envolveu as percepções das participantes em relação ao que julgavam importante cuidar na saúde da mulher e consistiu na confecção de um álbum sobre o cuidado, pelas técnicas de recorte e colagem. Para isso, foi afirmado às participantes o seguinte: "Todas somos mulheres e vivenciamos o nosso cuidado desde que nascemos. Se tivéssemos um álbum, falando das nossas vivências, sentimentos e percepções sobre o cuidado à saúde, ao longo da vida, como ele seria?".

Mediante a realização das técnicas e dinâmicas, pode-se constatar um comportamento das participantes semelhante ao citado em outro estudo que também utilizou a grupo focal ${ }^{3}$ como técnica de produção dos dados. Com a vivência da dinâmica no grupo, esses autores relataram que o debate ocorreu de maneira criativa, divertida e sem qualquer censura, da mesma forma como se deu no presente estudo, com a expressão natural de sentimentos, percepções e ideias de todas as participantes.

Durante o debate, considerado o quarto momento grupal, a moderadora utilizou questionamentos simples e genéricos para manter acesa a discussão. Com o desenvolvimento do debate, ela passou a introduzir questionamentos mais específicos sobre a temática, já previstos no roteiro, para promover o aprofundamento da discussão ${ }^{2}$.

Por fim, no quinto momento de cada encontro, foi apresentada uma síntese do debate, com validação coletiva das falas. Nesse momento, as participantes tinham a oportunidade de acrescentar, esclarecer ou modificar alguma ideia proposta na discussão 3,11 .

Nos encontros subsequentes, antes de iniciar cada encontro, era apresentada a síntese do encontro anterior, a fim de garantir mais um espaço para que as mulheres pudessem acrescentar ou retirar alguma ideia, mas também para que pudessem acompanhar a lógica de continuidade proposta das temáticas. Somente depois, era apresentado o objetivo daquele encontro e realizada a orientação para realização da dinâmica ou técnica estimuladora do debate subsequente, conforme operacionalização aconselhada na literatura ${ }^{3}$. Ao final da sessão, era confirmado o próximo encontro e entregue um cartão com um lembrete às participantes e, então, elas eram convidadas a lanchar.

O momento que antecedeu o início de cada sessão de grupo focal mostrou-se fundamental para que as mulheres que não haviam participado do encontro anterior pudessem apreender os debates desenvolvidos e também pudessem se posicionar. Portanto, verificou-se que a inserção de novas participantes no segundo e terceiro encontros não comprometeu a produção dos dados, pois todas tiveram oportunidade de se manifestar em diferentes momentos sobre os temas abordados, trazendo novas indagações e reflexões para serem discutidas no grupo. 
No que se refere à duração dos encontros, eles tiveram a duração de aproximadamente uma hora. Autores 2,6,11 recomendam a realização de sessões com duração entre uma a duas horas. Dentro dessa recomendação, acredita-se que todos os encontros permitiram a produção de dados necessários para uma boa análise e garantiram que não ocorresse cansaço ou desgaste mental das participantes.

Depois da retirada do campo de estudo, a cada encontro, a moderadora e o observador se reuniram para avaliar a operacionalização do grupo focal, trocar percepções sobre o desempenho de ambos e das participantes, esclarecer algumas ideias referidas pelas mulheres, e reorganizar orientações e/ou roteiro do próximo encontro 3,20. Considera-se que a avaliação e a reflexão conjunta de cada sessão de grupo focal foram fundamentais para organizar e qualificar as atividades subsequentes. Concernentemente ao exposto, autores16 afirmam que a condução da técnica de grupo focal implica pensar junto e trocar impressões sobre o desenvolvimento do grupo e os aspectos mais significativos de cada sessão. Logo, acredita-se que, no presente estudo, esses momentos aprimoraram o emprego da técnica.

No encerramento do último encontro, com vistas a avaliar o emprego da técnica de grupo focal, questionou-se a opinião das participantes quanto à metodologia utilizada e os debates grupais realizados. As percepções do grupo demonstraram apresentar sintonia, e as mulheres se relevaram satisfeitas em participar do estudo.

"Eu gostei, adorei" (M1).

"Foi maravilhoso" (M2).

"Foi bem bom" (M6)

Ainda se verificou que uma das participantes vislumbrou os encontros como uma oportunidade de troca de conhecimentos, sentimentos e opiniões na comunidade.

"Eu me senti bem, porque assim a gente para se encontrar é difícil. A gente tem que 'tá' fazendo uma coisa, fazendo outra. Pode ver nossas casinhas são tudo perto... E tu não vê ninguém. Então, hoje, assim, tudo foi bom. A gente se encontrou, a gente se viu, tudo junto. Coisas que a gente nunca conversou, hoje a gente conversou" (M11).

Quando indagadas sobre a participação em estudos ou atividades semelhantes, nas quais pudessem interagir com os pesquisadores, verbalizando suas vivências, ideias e sentimentos, elas referiram que nunca havia sido proposta nenhuma ação dessa natureza na comunidade. Com isso, afirmaram que aquela era a primeira vez que se sentiam ouvidas e podiam se expressar sem censuras.

Por mais que não seja essa a finalidade do grupo focal, ele permitiu que as participantes vivenciassem um momento grupal de trocas e convivência, referido por elas como importante. Ressalta-se, nesta direção, a necessidade de investir em atividades grupais que produzam novos sentidos e significados e que possam promover o diálogo e o intercâmbio de experiências e saberes, na tentativa de construir conhecimentos contextualizados e validados pelos indivíduos envolvidos. Somente assim, é possível qualificar ou transformar hábitos, comportamentos e atitudes individuais e coletivas 24 .

Em relação às dinâmicas utilizadas nos encontros para gerar o debate, verificou-se que elas apresentaram boa aceitação entre as participantes, visto que, ao longo dos encontros, foi possível perceber a descontração e a interação entre as mulheres e os coordenadores do grupo focal. Pontua-se que, de início, as participantes mostravam-se um pouco introvertidas. Entretanto, à medida que ocorriam as dinâmicas e os debates e estabelecia-se a aproximação, elas já verbalizavam com segurança seus pontos de vista, conforme aponta a participante a seguir.

"Foi bom [se referindo às técnicas, dinâmicas e atividades propostas], porque a gente, no primeiro dia, sente vergonha né? Mas, né, depois passa" (M3).

Nessa perspectiva, acredita-se, também, que o comportamento da moderadora e do observador, mostrando-se tranquilos e atentos às falas, auxiliou na formação de vínculo com as participantes e facilitou o desenvolvimento do debate proposto na técnica de grupo focal. Além disso, os objetivos do estudo estavam bem claros e definidos, o que trouxe maior segurança no transcorrer dos encontros. Acredita-se que isso possa ter sido evidenciado às participantes 11,16.

Constatou-se que a entrevista semiestruturada e as anotações nos diários de campo mostraram-se úteis, quando utilizadas como técnicas complementares ao grupo focal. A entrevista semiestruturada permitiu a caracterização socioeconômica e de saúde das participantes. Dessa forma, constatou-se que as mulheres participantes se encontravam na faixa etária entre os 14 e 56 anos de idade; a maioria possuía um relacionamento consensual; não realizava atividade remunerada e apresentava Ensino Fundamental incompleto. Em relação à religião, algumas eram católicas e outras evangélicas. A renda familiar mensal variava entre $\mathrm{R} \$ 70,00$ e $\mathrm{R} \$ 800,00$. Em média, a menarca dessas mulheres ocorreu entre os 12 e 14 anos, a coitarca entre os 17 e 18 anos, e a menopausa entre os 40 e 51 anos. Verificouse que 11 participantes já haviam engravidado e que o número de gestações teve uma variação de um a nove. Os partos vaginais variaram entre um e seis, as cesáreas entre um e três e os abor- 
tos entre um e dois. A maioria das mulheres afirmou ter realizado acompanhamento pré-natal, sem quaisquer complicações durante o período gravídico-puerperal e vivenciado o processo de amamentação durante 15 dias a cinco anos. A maioria havia realizado o exame citopatológico no ano anterior à pesquisa e não utilizava nenhum método contraceptivo.

Já os diários de campo foram relevantes durante o registro das observações sobre o debate grupal, as características da dinâmica do grupo e as impressões dos coordenadores da técnica sobre os temas abordados e a participação das mulheres. Nos diários, ainda foi possível incluir notas teóricas e metodológicas que auxiliaram na análise e discussão dos dados da pesquisa.

Quanto aos aspectos limitantes, destacou-se o fato de o observador ser um homem e o tema decorrido pautar-se nos cuidados de saúde que envolviam mulheres. Isso gerou certo desconforto inicial às participantes, conforme comentado por uma delas.

“Até eu comentei com as gurias... Ah, as gurias vão me dar razão, tu não te sente melhor conversando sobre esse assunto sem um homem perto?" (M10).

Depois de constatar que compartilhava um sentimento em comum com as demais participantes, ela ainda afirmou: "Tinha que ter um pouco mais de, assim, que privar as palavras que a gente queria falar, porque tinha um homem sentado junto com a gente. Por mais que ele nem abrisse a boca ali, né? Quietinho como ele estava, mas ele ia 'tá' escutando. Se tu falasse da menstruação, ia perguntar para ele: e tu? Como que foi pra ti menstruar?" (M10).

Anteriormente à realização do estudo, foi discutida a possibilidade de desconforto de alguma participante, ou de todas, com a presença de um indivíduo do sexo masculino na equipe. Contudo, como ele desenvolveria a função de observador e deveria apenas apoiar a moderadora no desenvolvimento da técnica, interagindo pouco com as participantes, considerou-se que sua presença não influenciaria no desenvolvimento da técnica. Porém, conforme visto na fala anterior, as mulheres se sentiram desconfortáveis.

O depoimento da participante evidencia a ideia de que, para as mulheres do estudo, existem, especificamente, assuntos de mulheres e assuntos de homens, e que para discuti-los mulheres e homens buscam os seus pares. Nesse contexto, é ponderado que os homens são socializados para falar sobre a mulher, mas não com a mulher ${ }^{25}$. Dessa forma, constatou-se que há dificuldade dessas participantes em partilhar com uma figura masculina o mesmo espaço de debate sobre aspectos que envolvem os cuidados com sua saúde, uma vez que essa situação mobiliza sentimentos de desconforto, vergonha, intimidação ou inibição.

Além dessa limitação, outras também foram identificadas e envolveram, entre outros fatores, a ansiedade da moderadora em aguardar o posicionamento das participantes, que, no primeiro encontro, sobretudo, mostraram-se retraídas e apresentaram muitos momentos de silêncio; e a dificuldade do observador em registrar o que não era dito pelas participantes, mas que foi observado e captado durante a produção dos dados.

Em relação ao "não dito", reconhece-se que é tão importante quanto a palavra informada, pois também consiste em uma fonte de comunicação 16,26. Autoras 9,16 explicam que o silêncio possui inúmeros significados e que pode ser resultado da intervenção do moderador, que interrompe o debate ou que se omite de realizar perguntas essenciais.

Ao mesmo tempo, o silêncio também pode se manifestar diante de um tema que soa como algo "novo", nunca pensado ou refletido. Diante disso, as pessoas tendem a ficar em silêncio para que possam organizar mentalmente suas ideias e, a seguir, manifestarem seus pontos de vista sobre a temática 27 . Possivelmente isso tenha ocorrido entre as participantes da pesquisa e pôde ser inferido pelo relato de uma delas, quando afirmou que nos encontros foram trabalhados temas que elas nunca haviam debatido.

Outro aspecto que pode ter representado uma limitação consistiu no desenvolvimento dos encontros de forma subsequente (todos na mesma semana), já que impossibilitou a transcrição das falas no mesmo dia e, com isso, a análise do encontro. Entretanto, vale ressaltar que, quanto à última situação, compreende-se que a realização dos encontros em sequência possibilitaram que os debates permanecessem vivos na memória das participantes, permitindo um aprofundamento crescente no grupo.

Outro aspecto considerado como limitante ao desenvolvimento do grupo focal foi a movimentação e o barulho causado pela presença dos filhos de uma das participantes no segundo e terceiro encontros, o que, por vezes, desviou a atenção das mulheres. Quanto a isso, autores referem a estratégia de organizar um espaço para recreação das crianças 11. Como os encontros aconteceram ao ar livre, por escolha das participantes, não havia um local apropriado para essa alternativa. Assim, optou-se por entregar materiais de desenho para que as crianças pudessem se distrair e permitir a participação das mulheres no encontro.

Ao utilizar a técnica de grupo focal na produção dos dados, também é preciso considerar 
que, durante o debate grupal, os participantes podem optar pela manifestação de tudo aquilo que entendem ser socialmente aceito e, por isso, os resultados podem apresentar situações que são aceitas pelo coletivo. Nesse sentido, todos os comportamentos e/ou atitudes desviantes raramente são expressas em grupo.

Por fim, por se tratar de um estudo que possuía como objeto de estudo o cuidado à saúde da mulher quilombola e que estava sendo conduzido por profissionais de saúde, em alguns momentos, as participantes realizaram questionamentos relacionados às suas práticas de cuidados de saúde ou condutas adotadas em algumas situações vivenciadas, para buscarem respostas aos seus problemas. Nessas situações, a moderadora informou que o esclarecimento seria realizado ao término do encontro. Reconhece-se que situações como essas são muito comuns quando a técnica de grupo focal é coordenada por um profissional de saúde, pois os indivíduos vislumbram como um momento adequado para dirimir suas dúvidas com aconselhamento profissional 9 .

Apesar das limitações identificadas na operacionalização da técnica de grupo focal, considera-se que os encontros grupais representaram espaços oportunos de construção do conhecimento, nos quais as mulheres se sentiram valorizadas e ouvidas em todas as suas necessidades, particularidades e singularidades. A fala, a seguir, demonstra essa constatação.

“A gente que agradece, né? De ter lembrado de nós” (M6).

Vislumbra-se, aqui, a importância da técnica de grupo focal ao ofertar às mulheres quilombolas a possibilidade de fala, escuta e divulgação de suas percepções, já que, historicamente, elas não tiveram oportunidade para tal. Ademais, com base nos dados produzidos com a técnica, considera-se que o objetivo da dissertação ${ }^{1}$ foi atingido e que mediante o conhecimento do significado do cuidado à saúde entre as mulheres quilombolas, a pesquisa permitiu auxiliar na elaboração de estratégias de cuidados direcionadas a esse grupo.

A técnica de grupo focal proporcionou a troca de ideias, experiências, sentimentos e valores, tornando possível momentos de reflexão 2,5,6. Com a utilização dessa técnica, verificou-se que as participantes eram as protagonistas do estudo, pois dialogaram e participaram ativamente da construção dos resultados da pesquisa 26 .

\section{Considerações finais}

Considera-se que a técnica de produção de dados utilizada permitiu o desvelamento de comportamentos, atitudes, sentimentos, percepções e vivências, sendo útil na identificação das reais necessidades da população estudada. Além disso, permitiu espaços produtivos de interação, debate e reflexão entre os pesquisadores e as mulheres quilombolas.

Acredita-se que, por meio da técnica de grupo focal, foi propiciado um ambiente condutor e estimulante para troca de experiências, percepções e sentimentos, tornando-se possível o pensar e refletir coletivamente. Mais do que isso, pôdese problematizar e aprofundar o significado das temáticas discutidas nos encontros. Portanto, a técnica de grupo focal representou um espaço propício para o conhecimento e a compreensão das experiências de vida das mulheres quilombolas, bem como os significados que atribuem a elas.

Verificou-se que a técnica exige a criatividade dos pesquisadores tanto no planejamento e organização das estratégias estimuladoras do debate, quanto na condução do encontro e nos desafios iminentes. Da mesma forma, exige flexibilidade para se adaptar às demandas e às possibilidades do grupo, bem como a sua estruturação prévia, aceitando a participação de indivíduos que não atendem aos critérios de inclusão da pesquisa mas que já estruturam o grupo e, por isso, precisam participar do debate grupal, embora suas manifestações não componham posteriormente o corpus de análise; atenção e respeito aos relatos e manifestações que emergem nos debates; ausência de julgamentos ao ouvir as experiências e condutas de cada sujeito; e preparação e conhecimento da técnica e da temática, por parte dos pesquisadores, para conduzir adequadamente os encontros. 


\section{Resumen}

Este estudio tiene como objetivo discutir sobre la experiencia del uso de la técnica de grupo focal en un estudio de mujeres quilombolas. Investigación cualitativa descriptiva, con aspectos antropológicos, llevada a cabo con 13 mujeres en una comunidad quilombola, situada en el Estado de Río Grande do Sul, Brasil. El uso de la técnica de grupo focal ha permitido la interacción y el intercambio de conocimientos, experiencias, percepciones y sentimientos, así como el cuestionamiento y la profundización sobre el significado del cuidado para la salud de la mujer quilombola. El grupo focal fue un espacio adecuado para el conocimiento y la comprensión de las experiencias de vida de las mujeres quilombolas, y los significados que atribuyen a las experiencias. La técnica de grupo focal requiere de los investigadores, la creatividad, la sensibilidad, la atención, el respeto, la falta de prejuicio, la flexibilidad, la preparación previa y el conocimiento de la técnica y el objeto de estudio.

Grupo de Ascendencia Continental Africana; Grupos Focales; Salud de la Mujer

\section{Colaboradores}

L. A. Prates contribuiu com a concepção do projeto e do manuscrito, produção dos dados, análise e interpretação, redação do artigo, revisão crítica do artigo e aprovação final da versão a ser publicada. F. G. Ceccon contribuiu com a concepção do manuscrito, produção dos dados, redação do artigo, revisão crítica do artigo e aprovação final da versão a ser publicada. C. N. Alves contribuiu com a análise e interpretação, redação do artigo, revisão crítica do artigo e aprovação final da versão a ser publicada. L. A. Wilhelm, C. C. Demori e S. C. Silva contribuíram com a análise e interpretação, revisão crítica do artigo e aprovação final da versão a ser publicada. L. B. Ressel contribuiu com a concepção do projeto e do manuscrito, produção dos dados, análise e interpretação, revisão crítica do artigo e aprovação final da versão a ser publicada.

\section{Agradecimentos}

À Coordenação de Aperfeiçoamento de Pessoal de Nível Superior (Capes) pelo apoio financeiro.

\section{Referências}

1. Prates LA, Scarton J, Barreto CN, Cremonese L, Possati AB, Ressel LB. Olhar feminino sobre o cuidado à saúde da mulher quilombola: nota prévia. Rev Enferm UFPE On Line 2014; 8(7). http:/ / www. revista.ufpe.br/revistaenfermagem/index.php/re vista/article/view/5961.

2. Gatti BA. Grupo focal na pesquisa em Ciências Sociais e Humanas. Brasília: Líber Livro Editora; 2005.

3. Ressel LB, Beck CLC, Gualda DMR, Hoffmann IC, Silva RM, Sehnem GD. O uso do grupo focal em pesquisa qualitativa. Texto \& Contexto Enferm 2008; 17:779-86.
4. Bisol CA. Estratégias de pesquisa em contextos de diversidade cultural: entrevistas de listagem livre, entrevistas com informantes-chave e grupos focais. Estud Psicol (Campinas) 2012; 29:719-26.

5. Iervolino SA, Pelicioni MCF. A utilização do grupo focal como metodologia qualitativa na promoção da saúde. Rev Esc Enferm USP 2001; 35:115-21.

6. Bauer MW, Gaskell G. Pesquisa qualitativa com texto, imagem e som: um manual prático. Petrópolis: Editora Vozes; 2008

7. Minayo MCS. Construção de indicadores qualitativos para avaliação de mudanças. Rev Bras Educ Méd 2009; 33:83-91. 
8. Backes DS, Colomé JS, Erdmann RH, Lunardi VL. Grupo focal como técnica de coleta e análise de dados em pesquisas qualitativas. Mundo Saúde $2011 ; 35: 438-42$

9. Barbour R. Grupos focais. Porto Alegre: Artmed; 2009.

10. Ressel LB, Budó MLD, Junges CF, Sehnem GD, Hoffmann IC, Büttenbender E. O significado de sexualidade na formação de enfermeiros. Rev Enferm UFPE On Line 2010; 4:631-8.

11. Mazza VA, Melo NSFO, Chiesa AM. O grupo focal como técnica de coleta de dados na pesquisa qualitativa: relato de experiência. Cogitare Enferm 2009; 14:183-8.

12. Minayo MCS. O desafio do conhecimento científico: pesquisa qualitativa em saúde. 14a Ed. São Paulo: Editora Hucitec; 2014.

13. Francisco KMS, Sundefeld MLMM, Garbin AJI, Garbin CAS. Técnica do grupo focal como método de avaliação do conhecimento de adolescentes sobre saúde bucal. Acta Sci Health Sci 2009; 31: 165-70.

14. Busanello J, Lunardi Filho WD, Kerber NPC, Santos SSC, Lunardi VL, Pohlmann FC. Grupo focal como técnica de coleta de dados. Cogitare Enferm 2013; 18:358-64.

15. Damico J. Corpo a corpo com as jovens: grupos focais e análise de discurso na pesquisa em educação física. Movimento (Porto Alegre) 2006; 12: 35-67.

16. Dall'Agnol CM, Trench MH. Grupos focais como estratégia metodológica em pesquisas na enfermagem. Rev Gaúch Enferm 1999; 20:5-25.

17. Victora CG, Knauth DR, Hassen MNA. Pesquisa qualitativa em saúde: uma introdução ao tema. Porto Alegre: Tomo Editorial; 2000.

18. Severo TP, Fonseca AD, Gomes VL. O. Grupo focal como técnica de coleta de dados na pesquisa em enfermagem. REME Rev Min Enferm 2007; 2: 297-302.
19. Veronese AM, Oliveira DLLC. Desenvolvendo pesquisa com grupos focais: experiência com motoboys. Online Braz J Nurs 2006; 5(3). http://www. objnursing.uff.br/index.php/nursing/article/ view/548/125.

20. Aschidamini IM, Saupe R. Grupo focal - estratégia metodológica qualitativa: um ensaio teórico. Cogitare Enferm 2014; 9:9-14.

21. Sehnem GD, Ressel LB, Junges CF, Silva FM, Barreto $\mathrm{CN}$. A sexualidade na formação acadêmica do enfermeiro. Esc Anna Nery Rev Enferm 2011; 17:90-6.

22. Trad LAB. Grupos focais: conceitos, procedimentos e reflexões baseadas em experiências com o uso da técnica em pesquisas de saúde. Physis (Rio J.) 2009; 19:777-96.

23. Audi CAF, Corrêa MAS, Turato ER, Santiago SM, Santiago SM, Andrade MGG, et al. Percepção da violência doméstica por mulheres gestantes e não gestantes da cidade de Campinas, São Paulo. Ciênc Saúde Coletiva 2009; 14:587-94.

24. Alves VS. Um modelo de educação em saúde para o Programa Saúde da Família: pela integralidade da atenção e reorientação do modelo assistencial. Interface Comun Saúde Educ 2005; 9:39-52.

25. Gomes R, Moreira MCN, Nascimento EFN, Rebello LEFS, Couto MT, Schraiber LB. Os homens não vêm! Ausência e/ou invisibilidade masculina na atenção primária. Ciênc Saúde Coletiva 2011; 16:983-92.

26. Dall'Agnol CM, Magalhães AMM, Mano GCM, Olschowsky A, Silva FP. A noção de tarefa nos grupos focais. Rev Gaúch Enferm 2012; 33:186-90.

27. Fontanella BJB, Campos CJG, Turato ER. Coleta de dados na pesquisa clínico-qualitativa: uso de entrevistas não dirigidas de questões abertas por profissionais da saúde. Rev Latinoam Enferm 2006; 14:174-83.

Recebido em 21/Jan/2015

Versão final reapresentada em 04/Jun/2015 Aprovado em 04/Ago/2015 